\title{
Proline, ornithine, arginine and glutamic acid contents in detached rice leaves
}

\author{
C.-W. YANG, C.C. LIN and C.H. KAO** \\ Department of Agronomy, National Taiwan University, Taipei 106. Taiwan. Republic of China
}

\begin{abstract}
The effects of water stress on the contents of proline, ornithine, arginine and glutamic acid in detached rice leaves were examined. In water stressed leaves, the content of proline was elevated to a content approximately 8-, 14- and 17-fold higher than in control leaves after 4,8 and $12 \mathrm{~h}$, respectively. We also observed that ornithine and arginine contents were much higher under water stress than in control leaves. However, the content of glutamic acid in water stressed leaves was higher after 4 and $8 \mathrm{~h}$ and lower after $12 \mathrm{~h}$ than that in control leaves.
\end{abstract}

Additional key words: amino acids, Oryza sativa, protein, water stress.

Proline often accumulates in plants subjected to water stress (e.g. Munns et al. 1979, Kao 1981, Venckamp and Kost 1988, Mattioni et al. 1997, Yoshiba et al. 1997). I1 has been shown that pyrroline-5-carboxylate synthetase, which acts during the biosynthesis of proline, and proline dehydrogenase, which acts during the degradation of proline, appear to be the rate-limiting factors responsible for proline accumulation in water-stressed plant tissues (Yoshiba et al. 1997). Recently, we have shown that a decrease in proline utilization might contribute to water stressed-induced proline accumulation in detached rice leaves (Yang et al. 2000). Very little, if any, is known whether the contents of three amino acids (glutamic acid, ornithine and arginine) involved in the proline biosynthetic pathway are limiting factors for proline accumulation in plant tissues. The main question has been addressed in this paper: Is the concentration of glutamic acid, ornithine and arginine related to proline accumulation in detached rice laves caused by water stress?

Rice (Oryza sativa L., cv. Taichung Native 1) seedlings were cultured as previously described (Yang $e t \mathrm{al}$. 2000). The apical $3-\mathrm{cm}$ segments were excised from the third leaves of 12-d-old seedlings. Groups of twenty leaf segments were exposed to slightly decreased relative humidity (RH) above a solution of $0.5 \mathrm{M} \mathrm{NaCl}$. Similar segments of leaves were floated on $20 \mathrm{~cm}^{3}$ of distilled water in a Petri dish to serve as control. Water stress was judged by determination of relative water content (RWC) according to Mukherjee and Choudhuri (1983). All samples were incubated at $27^{\circ} \mathrm{C}$ and irradiance $40 \mu \mathrm{mol}$ $\mathrm{m}^{-2} \mathrm{~s}^{-1}$. For determination of glutamic acid, ornithine, arginine, proline, and total amino acids, leaf samples were extracted with boiling $80 \%$ ethanol for $15 \mathrm{~min}$, when the leaves were totally bleached. The extract was reduced to about $1 \mathrm{~cm}^{3}$, the volume was adjusted to $2 \mathrm{~cm}^{3}$ with distilled water and centrifuged at $1000 \mathrm{~g}$ for $90 \mathrm{~s}$. The clear supernatant liquid was used directly for amino acid analysis (amino acid analyzer, Beckman 6300, Palo Alto, USA). For protcin determination, leaf segments were homogenized in $50 \mathrm{mM}$ sodium phosphate buffer (pH 6.8). The homogenate was centrifuged at $17600 \mathrm{~g}$ for $20 \mathrm{~min}$, and the supernatants were used for determination of protein by the method of Bradford (1976). All data were expressed on the basis of initial fresh mass.

Received 13 Septembcr 1999, accepted 1 November 1999.

Abbreviations: f. m. - fresh mass; RH - relative humidity; RWC - relative water content.

Acknowledgement: This work was supported by the National Science Council, the Republic of China, grant 89-2313-B-002-111.

* Author for correspondence; fax: (+886)-2-2362-0879. c-mail: kaochalacems.ntu.edu.tw 
All experiments were repeated three times; within each experiment, treatments were replicated 4 times.

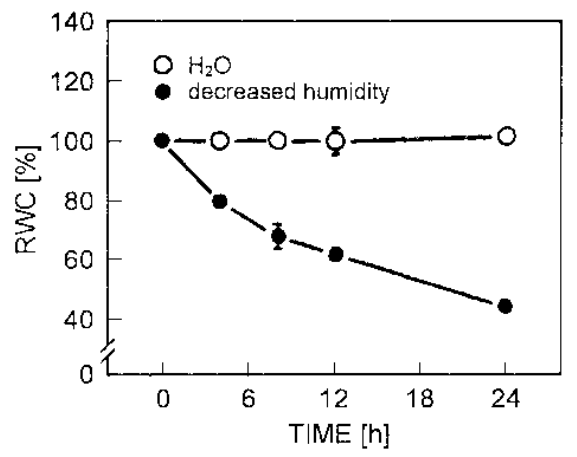

Fig 1. Relative water content (RWC) in detached rice leaves floating on water $\left(\mathrm{H}_{2} \mathrm{O}\right)$ or exposed to slightly decreased air humidity above $0.5 \mathrm{M} \mathrm{NaCl}$ (WS) for 4,8 and $12 \mathrm{~h}$. Vertical bars represent SF: $(n=4)$. Only those SE larger than symbol size are shown.
Similar results and identical trends were obtained in all experiments. The data reported here are from a single experiment.

Relative water content (RWC) of leaf segments exposed above a $0.5 \mathrm{M} \mathrm{NaCl}$ under light decreased considerably during 24-h treatment (Fig. 1), indicating that the treatment indeed cause water stress.

In control leaves, proline content decreased after 4-h treatment and then increased slightly (Table 1). Proline content in detached rice leaves exposed to the decreased air humidity (water stressed, WS) was increased to a contents about 8-, 14- and 17-fold higher than those in control leaves at 4,8 and 12 h, respectively (Table 1 ).

The decline in protein content during 12-h incubation was faster in WS than in control leaves (Table 1). Therefore, protein degradation might contribute to the water stress-induced proline accumulation. This conclusion is supported further by the observation that total amino acid content in detached rice leaves was higher under water stress than in controls (Table 1).

Table 1. Contents of proline, glutamic acid, ornithine, arginine $\left[\mathrm{nmol} \mathrm{g} \mathrm{g}^{-1}\left(\mathrm{f} . \mathrm{m}\right.\right.$.)], protcin $\left[\mathrm{mg} \mathrm{g}^{-1}(\mathrm{f} . \mathrm{m}\right.$.)], and total amino acids $\left[\mu \mathrm{mol} \mathrm{g}^{-1}(\mathrm{f} . \mathrm{m}).\right]$ in detached rice leaves floating on water $\left(\mathrm{H}_{2} \mathrm{O}\right)$ or exposed to decreased air humidity for 4,8 and $\mathrm{I} 2 \mathrm{~h}$ (WS).

\begin{tabular}{|c|c|c|c|c|c|c|c|}
\hline & \multirow[t]{2}{*}{$\mathrm{Oh}$} & \multicolumn{2}{|l|}{$4 \mathrm{~h}$} & \multicolumn{2}{|l|}{$8 \mathrm{~h}$} & \multicolumn{2}{|l|}{$12 \mathrm{~h}$} \\
\hline & & $\mathrm{H}_{2} \mathrm{O}$ & WS & $\mathrm{H}_{2} \mathrm{O}$ & WS & $\mathrm{H}_{2} \mathrm{O}$ & WS \\
\hline Proline & $162.8 \pm \quad 5.2$ & $135.8 \pm \quad 3.6$ & $1028.2 \pm 40.9$ & $275.8 \pm 4.0$ & $3963.2 \pm 96.3$ & $333.9 \pm \quad 6.1$ & $5587.3 \pm 130.4$ \\
\hline Glutamic acid & $5258.8 \pm 273.5$ & $3742.0 \pm 246.0$ & $7012.7 \pm 560.3$ & $5465.7 \pm 45.1$ & $8261.1 \pm 361.7$ & $6680.5 \pm 128.7$ & $5192.0 \pm 134.6$ \\
\hline Arginine & $376.6 \pm 18.9$ & $194.6 \pm \quad 4.1$ & $321.2 \pm 20.7$ & $136.1 \pm 3.8$ & $1208.8 \pm 54.0$ & $180.2 \pm \quad 5.8$ & $1088.7 \pm 14.1$ \\
\hline Ornitline & $12.9 \pm \quad 0.4$ & $6.4 \pm \quad 0.4$ & $18.6 \pm \quad 4.1$ & $9.1 \pm 0.1$ & $24.7 \pm \quad 2.4$ & $11.7 \pm \quad 0.6$ & $28.2 \pm \quad 0.8$ \\
\hline Protein & $58.2 \pm \quad 0.5$ & $58.3 \pm \quad 0.7$ & $49.7 \pm \quad 1.2$ & $57.8 \pm 2.6$ & $44.3 \pm \quad 0.8$ & $57.4 \pm \quad 1.0$ & $35.5 \pm \quad 0.9$ \\
\hline Amino acids & $15.6 \pm \quad 0.6$ & $\begin{array}{ll}3.5 \pm & 0.2\end{array}$ & $32.7 \pm \quad 2.5$ & $20.5 \pm 0.1$ & $62.5 \pm \quad 2.7$ & $23.8 \pm \quad 0.4$ & $63.1 \pm \quad 2.6$ \\
\hline
\end{tabular}

It is well established that glutamic acid, ornithine and arginine can all contribute to the accumulation of proline in plant tissues (Chiang and Dandekar 1995). Ornithine and arginine contents in detached rice leaves under water stress were much higher than those in control leaves (Table 1). However, glutamic acid content in detached rice leaves exposed to water stress was higher after 4 and $8 \mathrm{~h}$ and lower after $12 \mathrm{~h}$ than that in control leaves (Table 1). These observations suggest that higher contents of endogenous ornithine and arginine are associated with water stress-induced proline accumulation in detached rice leaves. Arginine can contribute to proline biosynthesis, and the pathway from arginine proceeds via ornithine as a result of catalytic activity of arginase (Brown and Fowden 1966). Since ornithine is more effective than arginine in increasing proline content in detached rice leaves (Yang et al. 2000), the contribution of ornithine pathway plays more determinant role in proline accumulation in detached rice leaves. In higher plants, it has been demonstrated that ornithine- $\delta$ aminotransferase participates in proline biosynthesis via ornithine pathway (Delauney et al. 1993, Roosens et al. 1988). However, our recent work showed that ornithine$\delta$-aminotransferase contributes little, if any, to proline accumulation in detached rice leaves under water stress condition (Yang and Kao 1999).

\section{References}

Bradford, M.M.: A rapid and sensitive method for the quantitation of microgram quantities of protein utilizing the principles of protein-dye binding. - Anal. Biochem. 72: 248-254, 1976.
Brown, D.H., Fowden, D.: Metabolism of delta-acetylornithinc in two leguminous species. - Phytochemistry 5: 887-892, 1966.

Chiang, H.-Il., Dandckar, A.M.: Regulation of proline 
accumulation in Arabidopsis thaliana (L.) Heynh. during development and in response to desiccation. - Plant Cell Environ. 18: 1280-1290, 1995.

Delauney, A., Hu, C., Kavi Kishor, P.B., Verma, D.: Cloning of ornithine- $\delta$-aminotransferase $\mathrm{CDNA}$ from Vigna aconitifolis by trans-complementation in Escherichia coli and regulation of proline biosynthesis. - I. biol. Chem. 268: 18673-18678, 1993.

Kao, C.H.: Senescence of rice leaves VI. Comparative study of the metabolic changes of sencscing turgid and water stressed excised lcaves. - Plant Cell Physiol. 22: 683-688, 1981.

Mattioni, C., Lacerenza, N.G., Troccoli, A., De Lconardis, A.M., Di Fonzo, N.: Water and salt stress-induced alterations in proline melabolism of Triticum durum seedlings. - Physiol. Plant. 101: 787-792. 1997.

Mukherjee, S.P., Choudhuri, M.A.: Implications of water stressinduced changes in the levels of endogenous ascorbic acid hydrogen peroxide in Vigna seedlings. - Physiol. Plant. 58: 166-170. 1983

Munns, R., Brady, C.J., Barlow, E.W.: Solute accumulation in the apex and leaves of wheat during water stress. - Aust. J. Plant Physiol. 6: 379-389. 1979.
Roosens, N.H.C.I., Thu, T.T., lskander, H.M., Jacobs, M.: Isolation of the ornithine- $\delta$-aminotransferase cDNA and effect of salt stress on its expression in Arabidopsis thaliana. - Plant Physiol. 117: 263-271, 1988.

Venckamp, J.H., Kost, J.T.M.: The sources of free proline and asparagine in field bean plants, Vicia faba L., during and after a short period of water withholding. - J. Plant Physiol. 132: $102-109,1988$.

Yang, C.W., Kao, C.H.: Importance of ornithine- $\partial-$ aminotransferase to proline accumulation caused by water stress in detached rice leaves. - Plant Growth Regul. 27: 189-192, 1999

Yang, C.-W., Y.in, C.C., Kao, C.H.: Endogenous ornithine and arginine contents and dark-induced proline accumulation in detached rice leaves. - I. Plant Physiol., in press, 2000.

Yang, C.-W. Wang. I.W. Kao. C.H.: The relation between accumulation of abscisic acid and proline in detached rice leaves. - Biol, Plant. 43: 30]-304, 2000.

Yoshiba, K., Kiyosue, T., Nakashima. K. YamaguchiShinozaki, K., Shinozaki, K.: Regulation of levels of proline as an osmolyte in plants under water stress. - Plant Cell Physiol. 38: 1095-1102. 1997. 